Bol. Acad. peru. leng. 65. 2019 (73-86)

\title{
LA METÁFORA CONCEPTUAL EN LA POESÍA QUECHUA CUSQUEÑA: UN ANÁLISIS SEMÁNTICO COGNITIVO DE NUNAYPA RURUN
}

\section{THE CONCEPTUAL METAPHOR IN CUSCO QUECHUA POETRY: A COGNITIVE SEMANTIC ANALYSIS OF NUNAYPA RURUN}

\author{
Diana Ibelice Conchacalle Cáceres \\ Universidad Nacional de San Antonio Abad del Cusco
}

\section{Resumen:}

En este trabajo se presenta un análisis de la metáfora como procedimiento semántico cognitivo en la obra Nunaypa rurun: frutos del alma (1993) de la poeta y antropóloga cusqueña Delia Blanco Villafuerte. El presente análisis se enmarca en la lingüística cognitiva, que explica la construcción de los conceptos a través de la relación existente entre el lenguaje, el pensamiento y la experiencia humana, cuyo logro es la estructuración de conceptos abstractos en dominios más concretos y cercanos a la experiencia.

Abstract:

This paper introduces an analysis of metaphor as a cognitive semantic procedure in the work Nunaypa rurun: frutos del alma (1993) by the Cusco poet and anthropologist Delia Blanco Villafuerte. This analysis is framed 
within Cognitive Linguistics, which explains the construction of concepts through the existing relationship between language, thought and human experience, whose achievement is the structuring of abstract concepts in domains more concrete and closer to experience.

Palabras clave: poesía, quechua, Cusco, metáfora, semántica cognitiva.

Key words: poetry, quechua, Cusco, metaphor, cognitive semantics.

Fecha de recepción:

Fecha de aceptación:
$02 / 03 / 2019$

$31 / 05 / 2019$

\section{Introducción}

La poesía quechua cusqueña es una manifestación que se caracteriza por presentar una temática ligada a la identidad cultural andina, la idiosincrasia propia del hombre andino definida por su cosmovisión, tal como se observa en otros poetas quechuas como Juvenal Pacheco, William Hurtado de Mendoza o Domingo Dávila Pezúa. La temática de los versos de Blanco Villafuerte es aun más variada y va desde los sentimientos propios del hombre andino hasta la respuesta que surge de las contingencias sociales y políticas. La temática presente en la obra de esta autora cusqueña también gira en torno al dolor ante la crisis, la reivindicación del poblador andino y, principalmente, de la mujer.

En esta investigación, se explican las metáforas presentes en los versos de Blanco, bajo un análisis semántico cognitivo. Para ello, se emplean los postulados de Lakoff y Johnson (1980) sobre la Teoría de la Metáfora Conceptual (TMC).

Esta teoría se aleja del enfoque retórico, donde se concebía a la metáfora como un mero recurso estilístico únicamente del lenguaje literario. 
En el análisis del trabajo, clasificaremos los datos en metáforas orientacionales y ontológicas. En estas últimas observaremos, por ejemplo, que el hombre andino le otorga una categoría de entidad humana a los fenómenos de la naturaleza, y es así como explica sus interrelaciones con el mundo que lo rodea.

\section{Delia Blanco Villafuerte en la poesía quechua contemporánea}

La poeta y antropóloga cusqueña Delia Blanco Villafuerte presenta Nunaypa rurun: frutos del alma, publicada en el año1993 por la Municipalidad del Cusco; muestra el sentir y el pensar del hombre andino en diferentes dimensiones, pues, como es sabido, en la poesía quechua contemporánea se expone la realidad que vive el hombre andino. Un rasgo muy resaltante es la aclamada reivindicación de los derechos vulnerados y el dolor que surge de estas situaciones de crisis colectiva. Pero, dentro de esta tendencia temática, Blanco Villafuerte hace un fuerte énfasis en la vulnerabilidad de la mujer andina y de los niños, y en este último caso, hace una denuncia social de la explotación laboral de la que son víctimas.

Otro rasgo saltante y muy llamativo en su obra es el tratamiento del amor nocivo, pues lejos de romantizarlo, como es común en la cultura occidental contemporánea, la autora muestra su rechazo con determinación y, suele denotar en sus versos feminismo y sororidad como medida de prevención para evitar relaciones tóxicas.

Blanco Villafuerte ha tenido una actividad cultural importante, destacada por su participación como miembro de la Academia Mayor de la Lengua Quechua durante los años 90. Esta labor y su producción literaria en quechua demuestran su afán por la preservación y difusión de esta lengua como vehículo del sentir, pensar y actuar del hombre andino, como parte de sus amplias pretensiones de reivindicación y visibilidad.

\section{La metáfora cognitiva}

Partiendo de un enfoque cognitivo de la lingüística, una de las habilidades a la que se presta más atención, en cuanto a la construcción 
de significados, es la capacidad de conceptualización o representación mental (Cuenca \& Hilferty, 1999).

Por su parte, Serra (s.f.) afirma que el estudio lingüístico cognitivo se centra en establecer las relaciones entre el pensamiento, la lengua y la experiencia humana. Por ello, explica que el lenguaje está basado en la naturaleza del mundo y es parte de la cognición humana. Para él, el lenguaje no está aislado de otros procesos, tales como la percepción y la experiencia. Es así que construimos nuestros conceptos a través de lo que vivimos. Ruiz de Mendoza Ibáñez y Galera Masegosa (2010) también indican que estos otros procesos cognitivos constituyen nuestro universo conceptual.

Lakoff y Johnson (1980) plantean la Teoría de la Metáfora Conceptual (TMC), en la cual la metáfora se analiza bajo un criterio cognitivo y como un esquema integrado al sistema conceptual, lo que hace que esté presente en todo tipo de discurso y pensamiento. Así, el ser humano hace uso de la metáfora sin percatarse de ello. Godenzzi (1999) considera a los procesos metafóricos como parte fundamental de la cognición humana.

Lejos de la concepción retórica, y ya desde una perspectiva cognitiva, Lakoff y Johnson (1980) sostienen que la metáfora es un proceso en el que se expresa y comprende una idea o fenómeno abstracto en términos de uno más concreto y cercano a la experiencia corpórea, perceptual y espacial, que son las primeras interacciones que tenemos con nuestro entorno. Para esto, hacemos uso de dos dominios: un dominio fuente y un dominio meta. El dominio fuente abarca lo más concreto y cercano al realismo experiencial, este hace una proyección conceptual o mapeo en el dominio meta (el más abstracto). Lakoff y Kövecses (citados en Cuenca \& Hilferty, 1999) explican que la proyección conceptual constituye una serie de correspondencias ontológicas, que se encarga de enlazar las subestructuras del dominio fuente con las del dominio meta, y correspondencias epistémicas, que explican el contenido que se exporta al dominio meta desde el dominio fuente. 
La Teoría de la Metáfora Conceptual propone una categorización de metáforas en estructurales, sontológicas y orientacionales. (Lakoff \& Johnson, 1980). Cabe resaltar que no se trata de una clasificación o división, ya que estas categorías no son excluyentes, sino más bien, son las características de la metáfora en general.

Lakoff y Johnson (1980) definen a la metáfora ontológica como aquella en la que se considera un determinado fenómeno como una entidad, sustancia, persona, recipiente. Se trata de atribuir una existencia física a fenómenos que carecen de ella. (Gálvez Astorayme \& Gálvez Gálvez, 2013) Las metáforas ontológicas se explican por el experiencialismo que el ser humano experimenta con el mundo que le rodea; es así que recurrimos a la personificación, animicidad, etc. (Gálvez Astorayme \& Gálvez Gálvez, 2013). Las metáforas orientacionales son metáforas de base corporal y espacial, en las que situamos fenómenos y experiencias humanas en espacios o escalas, tales como arriba/abajo, cerca/lejos, adelante/atrás, etc. Estas metáforas se caracterizan por presentar una base física que explica la proyección conceptual (Lakoff \& Johnson, 1980).

\section{Metodología}

Para la obtención del corpus lingüístico, se ha recurrido a la búsqueda de poetas cusqueños en las bibliotecas de la ciudad del Cusco. El poemario Nunaypa rurun: frutos del alma (1993) ha sido elegido de entre algunos autores y autoras por la más amplia diversidad presente en los temas tratados por la autora cusqueña.

Para el análisis del corpus, se ha recurrido a la Teoría de la Metáfora Conceptual (TMC) (Lakoff \& Johnson, 1980) que postula un enfoque cognitivo en el estudio y análisis de la metáfora. El análisis está clasificado en metáforas ontológicas y orientacionales.

El objetivo de este trabajo es analizar las expresiones metafóricas desde el enfoque de la lingüística cognitiva, que integra a los procesos cognitivos como parte del sistema lingüístico para la construcción de los conceptos. 


\section{Análisis metafórico}

\subsection{Metáforas ontológicas}

\subsubsection{Metáfora ontológica de animicidad}

En estas metáforas se hace un tratamiento semántico de los fenómenos no animados en términos de plantas, animales y seres animados: es decir, se les otorga alguna forma de vida no humana.

Se puede ver en las siguientes expresiones metafóricas del poema Kiska (Espino):

Amu qhasqoykipin, paqarirqan buj t'ika qhasqoykipi kiskata tarispa, mit'a puriqtin, chay t'ikanaq'erpurqan kiskallan qheparirkan.

(Nunaypa rurun, 1993: 108)

\author{
En el silencio de tu pecho nació \\ una flor \\ encontrando espinosos tus \\ sentimientos, \\ al correr el tiempo, se marchitó \\ solo quedaron los espinos.
}

(Nunaypa rurun, 1993: 109)

Metáfora: EL AMOR ES UNA PLANTA

Dominio fuente: la planta

Dominio meta: el amor

El amor es conceptualizado como una planta, que da flores, que se marchita (lo que indica su esplendor y decadencia, respectivamente), y que al tornarse nocivo y doloroso, se conceptualiza como «espinoso»; es decir, se concibe al amor doloroso como un objeto punzocortante. Esto último significa que estructuramos el dolor emocional en el dolor físico. 


\subsubsection{Metáfora ontológica de personificación}

Es aquella metáfora en la que se conceptualiza determinado fenómeno en tanto a un ser humano, pues se le atribuye acciones y comportamiento netamente humanos (Lakoff \& Johnson, 1980).

Gálvez Astorayme y Gálvez Gálvez (2013) explican que la personificación también se da por la extensión de una determinada cualidad.

Se observa en las siguientes expresiones metafóricas de los poemas presentados a continuación:

a) Llaqta Mama (Madre campesina)

Chiri wayrallas much'aykun

kbutuchasqa uyaykita

iphu parallas, pallarin samayniykita.

Umiña chbullallas, kiskachasqa chakiykita, mayllirinmaywaykuspa.

Ichari, naq'eriq qoraq llaqollanchu mach'aykusunki sayk'uyniykipi amachaykuspa llanthuykusunki.

(Nunaypa rurun, 1993:72)
Solo el viento frío besa tu entumido rostro recoge tu aliento, la insistente garúa.

La joya preciosa del rocío lava tus agrietados pies, acariciando las heridas, que te abrieron los espinos
Quizá la sombra de la maleza en su marchito manto protege tu cansancio.

(Nunaypa rurun, 1993:73)

Metáfora: LOS ELEMENTOS DE LA NATURALEZA SON PERSONAS

Dominio fuente: personas

Dominio meta: los elementos de la naturaleza

En este caso, la hierba, el viento y el rocío son personificados y adquieren atributos de agentivización, que, como explican Gálvez Astorayme y Domínguez Chenguayen (2015), consiste en atribuir responsabilidad e 
intencionalidad al fenómeno del que se habla en cuestión. Los elementos y fenómenos de la naturaleza son conceptualizados como entidades humanas o son atribuidos de tales rasgos debido a la interacción directa que el hombre andino tiene con el mundo que lo rodea. Esta integración hombre-naturaleza está reflejada en las expresiones lingüísticas (Villafán Broncano \& Olórtegui Mariño, 2016). Grillo (1990) asevera que, en la cosmovisión andina, el hombre necesita ver, sentir, tocar, etc., para conceptualizar el mundo que lo rodea. Es a través de los elementos de la naturaleza que estructura sus deseos, sentimientos y pensamientos.

b) Intiq churin (Vátago del sol)

Intiq churin hatariy
yuyay kallpata churaspa

(Nunaypa rurun, 1993: 60)
Vástago del sol, levántate por tu fuerza e inteligencia

(Nunaypa rurun, 1993: 61)

Metáfora: LOS ELEMENTOS DE LA NATURALEZA SON PROGENitoreS

Dominio fuente: progenitores

Dominio meta: los elementos de la naturalezaa

En este caso, el sol, al ser una deidad en la cosmovisión andina, se expresa lingüísticamente como pariente o en relación de parentesco con el hombre, ya que, como indica Esterman (1998), el universo andino es como una casa y a las deidades se les atribuye fecundidad. Un caso similar ocurre con la expresión Pachamama, que significa 'Madre Tierra', en la que se aprecia una correspondencia femenina, mientras el sol tiene una correspondencia con lo masculino (Esterman, 1998).

\section{c) Kiska (Espino)}

mit'a puriqtin, chay t'ika naq'erpurqan kiskallan qbeparirkan.

(Nunaypa rurun, 1993: 108) al correr el tiempo, se marchitó solo quedaron los espinos.

(Nunaypa rurun, 1993: 109) 
Metáfora: EL TIEMPO ES MOVIMIENTO

Dominio fuente: movimiento

Dominio meta: el tiempo

El tiempo se conceptualiza como una persona en movimiento que «camina» (como lo expresan los versos en quechua, o que «corre», como indica la versión castellana. Esta expresión metafórica presenta un modelo deíctico sin relación al yo, pues no se evidencia su direccionalidad (Faller \& Cuéllar, 2003).

\subsubsection{Metáfora ontológica de entidad o sustancia}

Son aquellas metáforas en las que se expresa un determinado fenómeno en términos de entidades o sustancias que pueden crecer o se pueden movilizar, reducir, cuantificar, etc. (Lakoff \& Johnson, 1980).

Se puede apreciar en las siguientes expresiones metafóricas:

a) Kiska (Espino)

Chaymi, ripullata yuyaykuni icha sispallapi phuyuman aypariyman aqoyraki kausaymanta ayqeriyman.

(Nunaypa rurun, 1993:108)
Por eso, solo pienso en irme quizá alcance a una cercana nube para buir de mis pesares.

(Nunaypa rurun, 1993:109)

Metáfora: LA NUBE ES UN VeHícUlo

Dominio fuente: vehículo

Dominio meta: la nube

Esta expresión metafórica contiene agentivización, lo que significa que expresa un fenómeno capaz de llevar a cabo determinada acción 
(Gálvez Astorayme \& Domínguez Chenguayen, 2015). La nube es conceptualizada como un vehículo o un objeto que se mueve, que avanza hacia una dirección, que nos lleva o nos aleja de nuestros sentimientos, lo que nos lleva a la deducción de la siguiente metáfora:

Metáfora: LOS SENTIMIENTOS SON LUGARES

Dominio fuente: lugares

Dominio meta: sentimientos

En los versos en quechua, el sentimiento que nombra la autora es la desgracia o el infortunio, que está cosificado como un lugar, pues ese es el sentimiento del que se quiere huir. En la versión castellana, la autora denomina pesares a este sentimiento que expresa lugar.

b) Llullay (Mi amor)

Ajnu killa tutapin, wiñallaña Por siempre te espero, en bellas noches de suyasayki luna

luluyniychis qellpuman ayparinanpa. así nuestro amor alcanzará la gloria.

(Nunaypa rurun, 1993:58)

(Nunaypa rurun, 1993:59)

Metáfora: EL AMOR ES UN OBJETO QUE SE MUEVE

Dominio fuente: objeto

Dominio meta: el amor

El amor está conceptualizado como un objeto que se mueve, que se desplaza, que alcanza. En esta expresión metafórica, el concepto del amor está siendo cosificado y dotado de agentivización. 


\subsection{Metáforas orientacionales}

Se aprecia en las siguientes expresiones metafóricas:

a) Intiq churin (Vástago del sol)

Tawantin suyu llaqtayuq hatariy, qheswakunapi kausaq runa

Qnparmanasqa, ullpusqa puriqtiykin yawarniyki tupanchiq runakunan suyuykiypi, chaqoq sisi waywarin; qanqa, kuntur hina raphraykita phalariy

antikunaq hawanta hoqarikuy k'ancabywan kuskachakuspa, illay.

Intiq churin batariy yuyay kallpata churaspa

(Nunaypa rurun, 1993: 60)
Tuyo es el pueblo, levántate, valiente hombre quechua Al verte gacho, humilde caminante, los que osaron mezclar tu sangre se levantan, hormigas destructoras. Tú, como el cóndor levanta tus alas álzate por encima de los andes une su fulgor, junto a tu lumbre.

Vástago del sol, levántate por tu fuerza e inteligencia

(Nunaypa rurun, 1993: 61)

b) Iman kawsay (Qué es vivir)

Kausayqa, kallpachakuspa hatariymi hark'aqniykita llallipaspa, picharinan nawiynchista matinchista oqarispa

(Nunaypa rurun, 1993: 70)
Vivir, es alzarse tomando fuerza y valor aunque la miseria nos aflija despejar el camino
levantando la frente

(Nunaypa rurun, 1993: 71)

Metáfora: CONTROL O FUERZA ES ARRIBA / ESTAR SUJETO A CONTROL O FUERZA ES ABAJO

En la primera expresión metafórica (a), hay un grupo dominante y un grupo dominado, mientras que, en la segunda expresión (b), levantar indica 'tomar fuerza'. 
La base física de esta metáfora orientacional radica en que la talla física se correlaciona con la fuerza y estatus de poder; así, una talla grande representa fuerza y poder, mientras que una baja, debilidad (Lakoff \& Johnson, 1980).

\section{Conclusiones}

La metáfora debe seguir un estudio semántico cognitivo, en lugar de uno retórico, pues así se aborda más ampliamente el lenguaje y pensamiento. Las metáforas ontológicas se manifiestan como cosificación, animicidad y personificación, y son las que dan vida o existencia física a diversos fenómenos de la realidad cotidiana. En la cosmovisión andina, el hombre necesita tener contacto directo con la naturaleza para entender el mundo. Es por ello que las expresiones poéticas (y toda expresión lingüística) recurren a las metáforas de personificación para explicar la relación entre el hombre, su entorno y sus fenómenos, como es el caso de los poemas Llaqta Mama e Intiq churin. Es vital el análisis de metáforas orientacionales en poemas donde el tema central es el sometimiento y la reivindicación del hombre andino, pues se usa un esquema de verticalidad para expresar esa relación de poder, este es el caso del poema Intiq churin, donde la situación política del hombre andino está expresada en escalas verticales (arriba/abajo). Las metáforas orientaciones expuestas en el trabajo se originan en una base corpórea. Siendo el amor, uno de los conceptos más abstractos, es expresado lingüísticamente como una planta en el poema Kiska. La mayoría de las expresiones metafóricas analizadas en este trabajo están presentes en el lenguaje cotidiano, lo que demuestra que la metáfora es una operación cognitiva recurrente en todo tipo de discurso. 
https://doi.org/10.46744/bapl.201901.004

\section{BIBLIOGRAFÍA}

BLANCO VILLAFUERTE, D. L. (1993). Nuanypa rurun: Frutos del alma. Cusco: Municipalidad del Cusco.

ESTERMAN, J. (1998). Filosofía Andina: Estudio intercultural de la sabiduría autóctona andina. Quito: Abya-Yala.

FALLER, M., \& CUÉLLAR, M. (2003). Metáforas del tiempo en el quechua. Actas del IV Congreso Nacional de Investigaciones Lingüístico Filológicas. Lima: Universidad Ricardo Palma.

GÁLVEZ ASTORAYME, I., \& DOMÍNGUEZ CHENGUAYEN, F. J. (2015). Animicidad y agentivización en las construcciones de la toponimia del quechua de Aurahuá-Chupamarca: un enfoque cognitivo. Escritura y pensamiento, 18(37), 153-175.

GÁLVEZ ASTORAYME, I., \& GÁLVEZ GÁLVEZ, Y. (2013). Metáforas ontológicas en el quechua ayacuchano: personificación y cosificación. Letras, 84(120), 237-247.

GODENZZI, J. C. (1999). Cognición y Lenguas Andinas. Apuntes, 2 (45), 97-106.

GRILLO, E. (1990). Cosmovisión andina y cosmología occidental moderna. Agricultura y cultura en los Andes, 116.

JOSEP CUENCA, M., \& HILFERTY, J. (1999). Introducción a la lingüística cognitiva. Barcelona: Editorial Ariel.

LAKOFF, G., \& JOHNSON, M. (1980). Metaphors We Live By. Chicago: The Chicago University Press.

RUIZ DE MENDOZA IBAÑEZ, F. J., \& GALERA MASEGOSA, A. (2010). Mecanismos cognitivos en la conceptualización del mundo: la metáfora. Cuadernos de neuropsicología, 4(2). 
SERRA, E. (s.f.). Fundamentos de Lingü̈stica Cognitiva. Valencia: Universitat de Valéncia.

VILLAFÁN BRONCANO, M., \& OLÓRTEGUI MARIÑO, R. (2016). Fórmulas de metaforización en el quechua ancashino. Revista Académica UNASAM, 3(4), 309-329. 